\title{
Erratum to: Third-line treatment of colorectal liver metastases using DEBIRI chemoembolization
}

Germano Scevola $^{1} \cdot$ Giorgio Loreni $^{1} \cdot$ Marco Rastelli $^{1} \cdot$ Stefano Sposato $^{1}$ Sara Ramponi ${ }^{2} \cdot$ Vittorio Miele $^{3}$ (1)

Published online: 6 April 2017

(C) Springer Science+Business Media New York 2017

\section{Erratum to: Med Oncol (2017) 34:37 \\ DOI 10.1007/s12032-017-0890-9}

The original version of the article unfortunately contained a mistake. The author of this article has not included the figures for this article. This is now corrected through this erratum, and the figures for this article are given (Figs. 1, 2 and 3).

The online version of the original article can be found under doi:10.1007/s12032-017-0890-9.

Germano Scevola germano.scevola@gmail.com

1 Department of Interventional Radiology, S. Pertini Hospital, Rome, Italy

2 Department of Medical Oncology, S. Pertini Hospital, Rome, Italy

3 Department of Radiology, Careggi University Hospital, Florence, Italy 
(a)

(b)

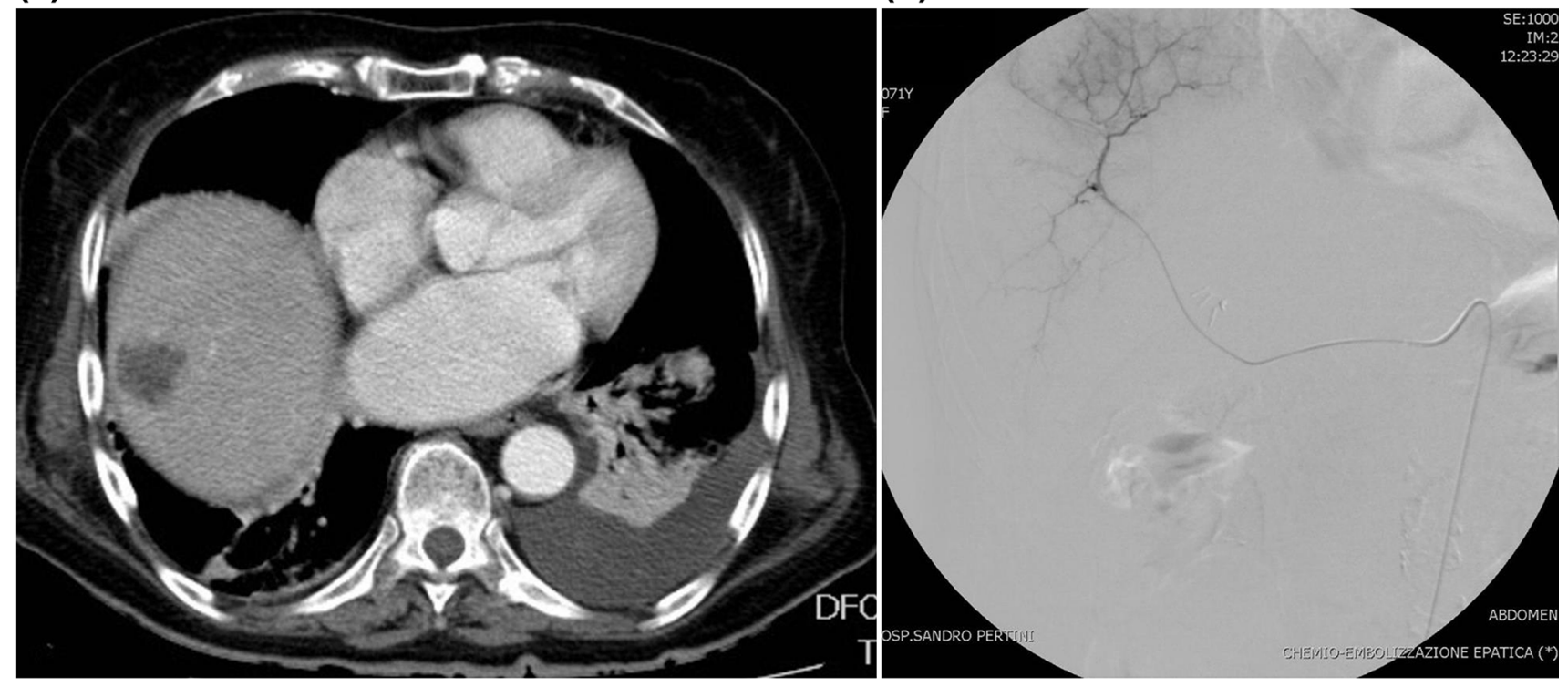

(c)

(d)

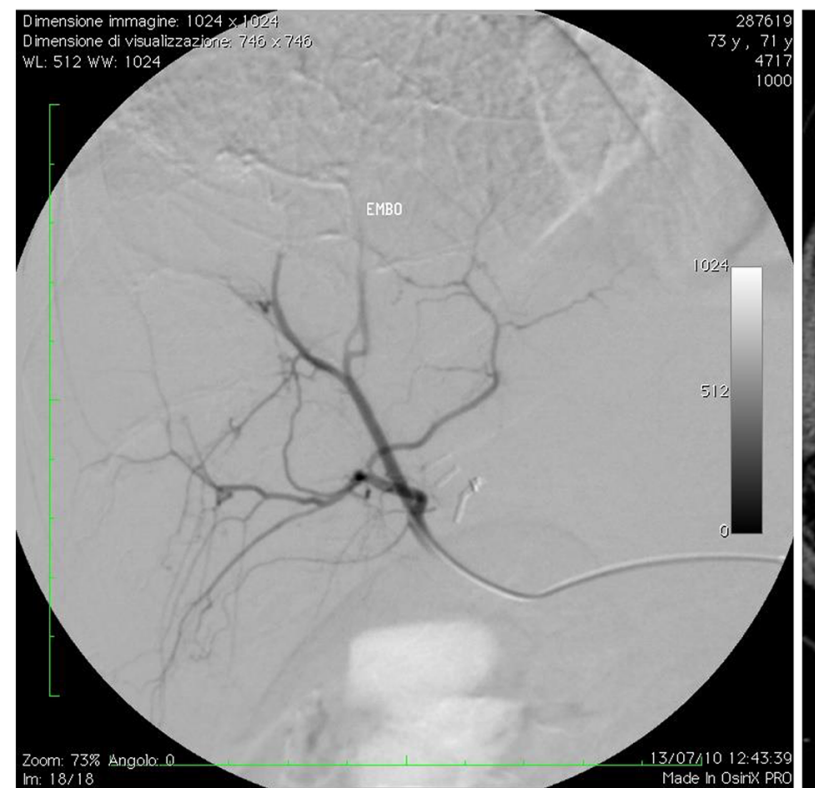

Fig. 1 Case $\mathrm{N}^{\circ} 1$. a CT scan, single focal liver metastasis from colorectal cancer in the VIII segment, $\mathbf{b}$ selective embolization of the VIII segment, c final check with selective catheterization of the hepatic artery at the end of treatment DEBIRI: embolization of

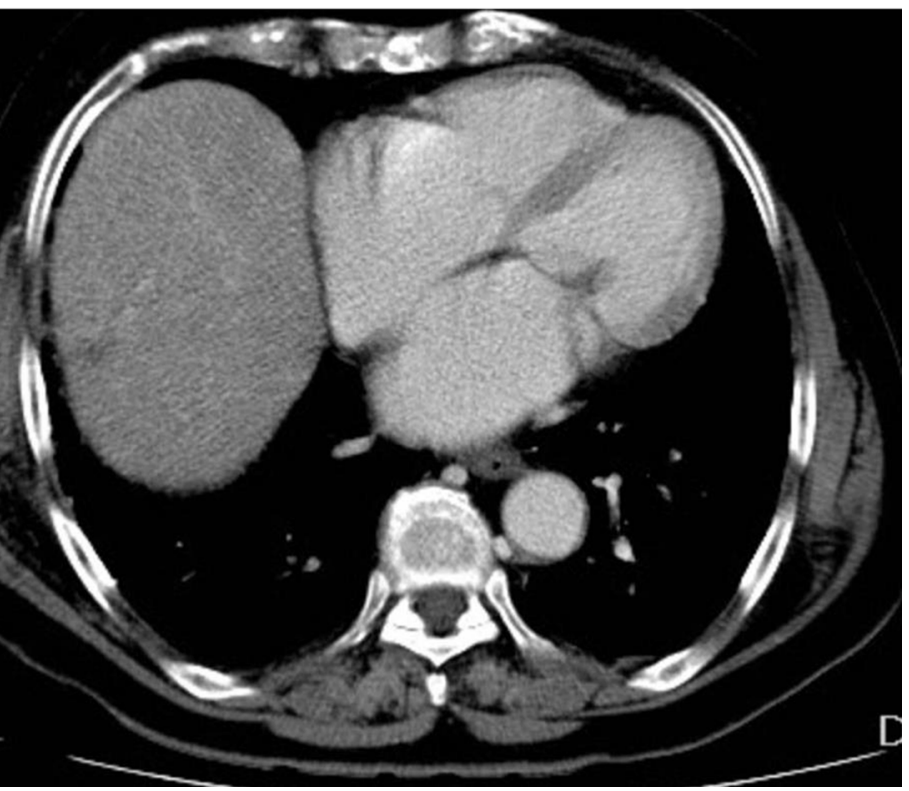

branches of VIII segment with stopping the flow, and d CT scan performed at 26-month follow-up demonstrates significant reduction in lesion 
(a)

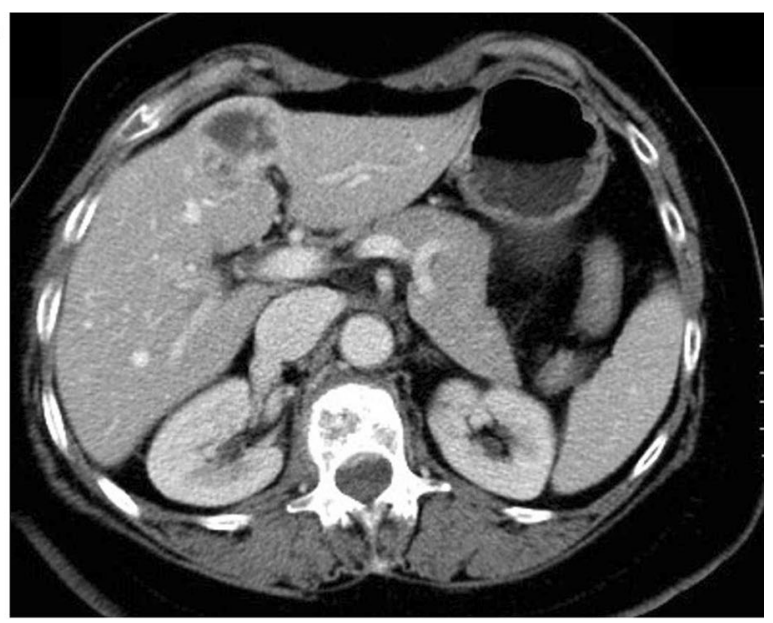

(b)

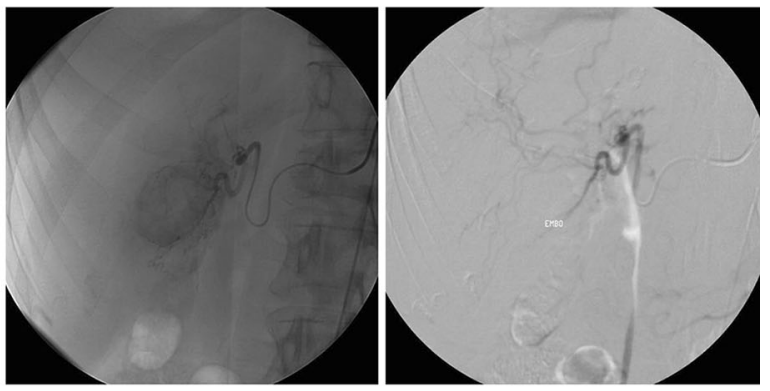

(c)

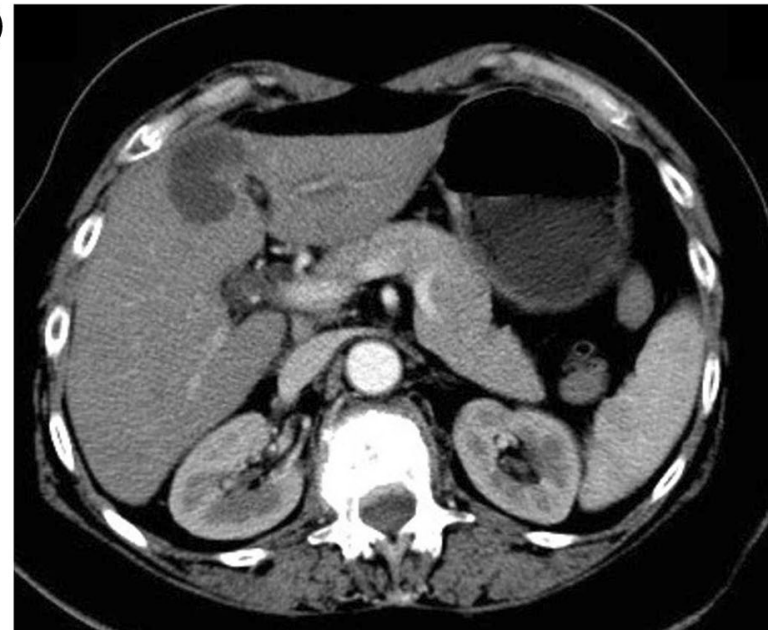

Fig. 2 Case $\mathrm{N}^{\circ}$ 2. a CT scan, single focal liver metastasis from colorectal cancer in the IV segment, b selective embolization and DEBIRI treatment of the segment IV, and $\mathbf{c}$ CT scan after 24 months demonstrates a hypodense necrotic metastasis in IV segment (a)

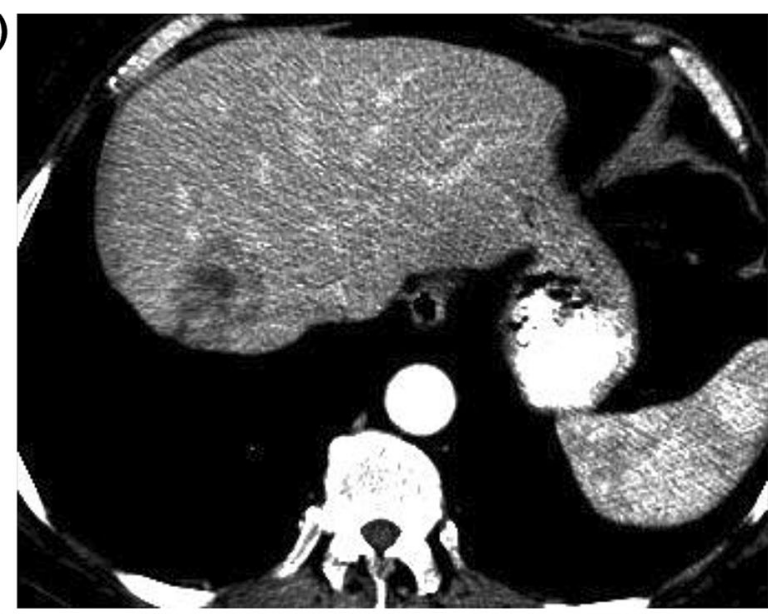

(b)

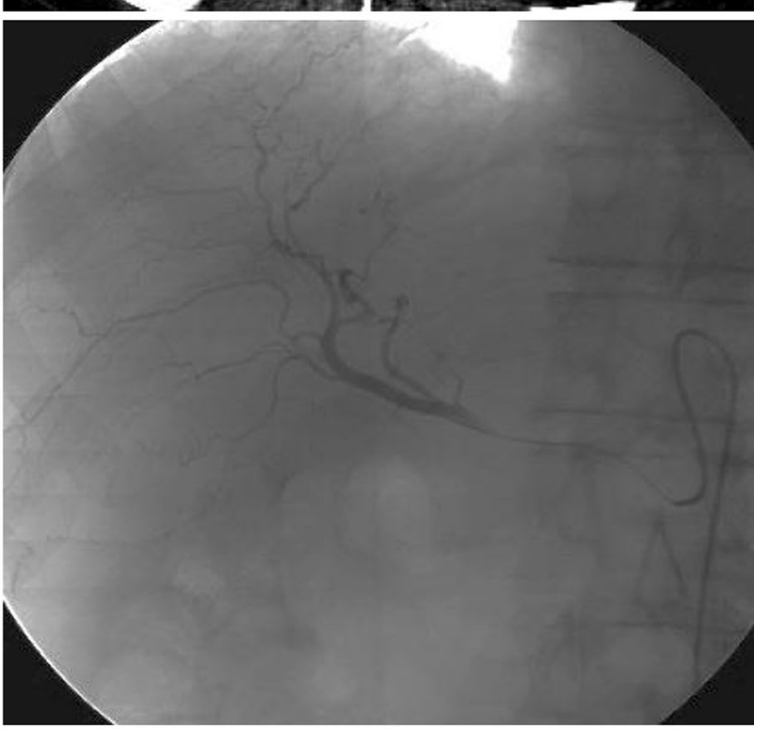

(c)

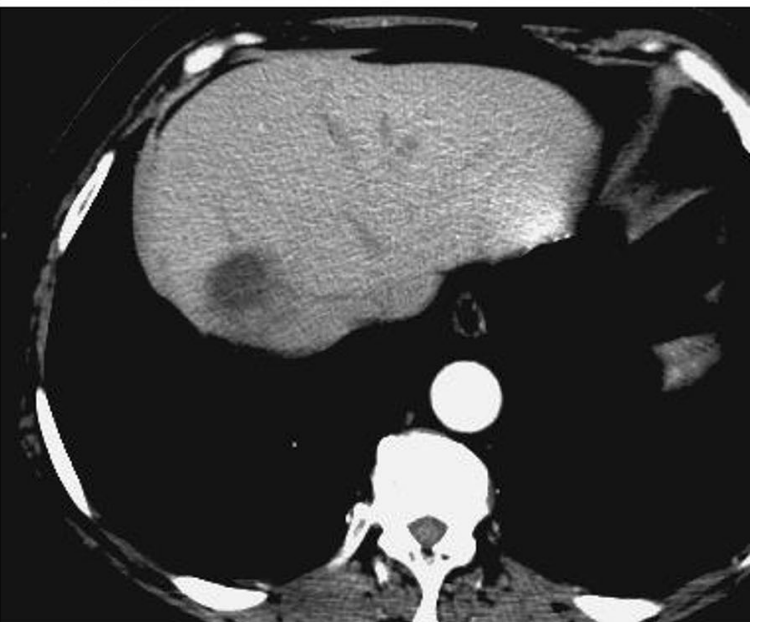

Fig. 3 Case $\mathrm{N}^{\circ}$ 3. a CT scan, recurrent single focal liver metastasis from colorectal cancer in the VIII segment, previously treated with RF thermoablation, $\mathbf{b}$ selective embolization and DEBIRI treatment of the segment VIII, and c CT scan after 32 months demonstrates a hypodense necrotic metastasis in VIII segment 